ISSN: 0213-2052 - eISSN: 2530-4100

DOI: https://doi.org/10.14201/shha202038191215

\title{
GENTILITAS, PECCATUM Y HUMANITAS \\ EN EL SERMÓN XX DE MÁXIMO DE TURÍN \\ (...398-...423). TRADUCCIÓN Y COMENTARIO
}

\section{Gentilitas, Peccatum and Humanitas \\ in the Sermon XX of Maximus of Turin \\ (...398-...423). Translation and Commentary}

\author{
Esteban NOCE \\ Universidad de Buenos Aires-(CONICET) \\ esteban.noce@gmail.com // esteban.noce@filo.uba.ar
}

Fecha de recepeción: 27-9-2019; aceptación definitiva: 21-2-2020

ORCID: https://orcid.org/0000-0003-2391-7084

RESUMEN: En estudios previos hemos sostenido que Máximo de Turín (...398-...423) empleó los términos gentilitas y paganismus para referir a dos entidades no solo diversas, sino incluso opuestas en algunas importantes características. En efecto, gentiles refería a los individuos que no conocían todavía el cristianismo, pero conservaban la posibilidad de devenir cristianos a la vez que salvos; pagani, en tanto, daba cuenta de quienes habían conocido el cristianismo pero lo habían rechazado, haciéndose por ello merecedores de la muerte eterna. El objetivo de este trabajo es profundizar nuestro conocimiento respecto del significado que al término gentilitas correspondió en los sermones del obispo a partir del análisis del sermón XX y de la particular relación que en él estableció Máximo entre gentilitas, peccatum y humanitas.

Palabras clave: Máximo de Turín; sermón XX; gentilitas; peccatum; bumanitas. 
ABSTRACT: We have held in previous papers that Maximus of Turin (...398- ...423) resorted to the terms gentilitas and paganismus in order to allude to two entities that were not only different, but even more, opposed in some fundamental characteristics. Indeed, gentilitas referred to individuals that had not known of Christianism yet but still conserved the possibility of becoming Christians and thus could still obtain salvation, whereas paganismus referred to those who had known of Christianism but decided to reject it, deserving eternal death. The aim of this paper is to go in depth in the knowledge of the meaning that Maximus attributed to the term gentilitas through the analysis of his sermon XX and the peculiar relationship he established there between gentilitas, peccatum and bumanitas. nitas.

Keywords: Maximus of Turin; sermon XX: gentilitas: peccatum: buma-

\section{INTRODUCCIÓN}

En el curso de los últimos años hemos llamado la atención respecto de un problema que ha caracterizado y afectado a los estudios sobre la vida y la obra de Máximo de Turín durante más de un siglo ${ }^{1}$. Nos referimos a la pretendida sinonimia que, de acuerdo a los traductores y a los comentaristas de sus Sermones ${ }^{2}$, habría existido en sus homilías entre los términos paganismus y gentilitas ${ }^{3}$. Esta asunción ha conducido a la inmensa mayoría de los investigadores a afirmar que la prédica maximiana exhibió una mayúscula preocupación respecto de una entidad histórica que habría estado consistentemente representada en Turín y sus alrededores -la gentilitas-paganismus-, la cual habría, además, sido caracterizada por el orador como manifiestamente negativa y peligrosa para la comunidad cristiana ${ }^{4}$.

1. Noce 2017, 177-202, artículo en que se realiza un análisis crítico de la bibliografía maximiana publicada entre 1898 (SAVIO 1971, 283-294) y 2014 (Weidmann 2014, 99-130; Eger 2014). En Noce 2019a, 176-179 incorporamos a nuestras consideraciones tres artículos que hasta entonces desconocíamos: Ariano, M. P. A. 2014; Ariano, M. L. 2014; Ariano, M. L. 2017. Aunque valioso en sí mismo, ninguna relevancia supone para la cuestión que aquí nos interesa el recientemente publicado WeIDMANN 2018.

2. MutzenBecher 1962. Seguiremos esta edición para todas nuestras alusiones a los sermones de Máximo, a los cuales aludiremos en las notas al pie como «S.». Todas las traducciones son propias.

3. NOCE 2019a, 171-182.

4. Tamassia 1911, 432-434; Bongiovanni 1952, 47; Gallesio 1975, 26; Spinelli 1983, 39-40; Ramsey 1989, 7; Lizzi 1989, 197; Banterle 1991, 15; Zangara 1992, 517; Zangara 1995, 53; De 
El análisis exhaustivo del sermón XLVIII, por el contrario, nos condujo a proponer que en el discurso de Máximo gentilitas y paganismus designaban a dos entidades históricas no solo diversas, sino incluso opuestas en sus rasgos fundamentales. En efecto, en tanto que el autor tenía por paganus a quien había conocido y rechazado el cristianismo, haciéndose por ello merecedor de la muerte eterna, con gentilis designaba a aquel que, desconociendo aún la uera fides, se hallaba sometido inocente e involuntariamente a los avatares de la existencia conservando, sin embargo, la esperanza de devenir cristiano a la vez que salvo ${ }^{5}$. Posteriormente, a partir de la consideración general de cada una de las 29 alusiones a los gentiles y a la gentilitas contenidas en los Sermones, hemos evidenciado, por una parte, que la caracterización del fenómeno gentil plasmada en ellas se condice con la realizada en el sermón XLVIII; por otro, que en ninguna se asigna a los gentiles los rasgos que en dicha homilía identifican a los pagani. Tales circunstancias nos permitieron afirmar que la concepción de la gentilitas presente en el sermón XLVIII no es exclusiva de este, sino que subyace al conjunto de la obra homilética del obispo de Turín 6 .

El desarrollo de nuestra labor nos lleva ahora a analizar detenida y particularmente las distintas homilías en que la gentilitas se halla presente, entendiendo que las consideraciones específicas que Máximo pudiese haber realizado en torno a ella en cada uno de estos sermones podría

Filippis Cappai 1995, 53-54; Modemann 1995, 15; Hamman, Plazanet-Siarri 1996, 9-10, 14; Merkt 1997, 106-108; Bolgiani 1997, 283; Bolgiani 1998, 123; De Filippis Cappai 1999, 53; Padovese 1999, 97-98; Devoti 1999, 101-102, 115; Maritano 1999, 129-130; Mariani Puerari 1999, 10, 64 , 83; Di Mauro 2001, 65-66; Banterle, Petri 2003, 17; Eger 2014, 46; Ariano 2014, 216.

5. Noce 2019a, 183-191.

6. Noce 2019b. Como hemos señalado oportunamente (Noce 2019a, 202; Noce, 2019b, no pretendemos que nuestras consideraciones respecto de los términos gentilis-gentilitas y paganus-paganismus resulten operativas para el análisis de la obra de otros autores eclesiásticos tardoantiguos. Por el contrario, insistimos en que la diferencia semántica que hemos establecido entre ambos se deriva exclusivamente del estudio de los Sermones de Máximo de Turín y, al menos por el momento, resulta aplicable tan solo a ellos. Únicamente la realización de estudios de caso diversos podría determinar si la pretendida sinonimia que habría correspondido en la literatura cristiana tardoantigua a los términos gentilis y paganus - a los que en ocasiones se añaden gens y profanus- encuentra sustento en otros contextos heurísticos o si, por el contrario y tal como se verifica en el corpus homilético maximiano, resulta de la aceptación acrítica de una presunción sin fundamento. Si bien no ahondan específicamente en la cuestión, vale la pena rescatar algunos trabajos que al menos han indagado sobre el significado que vocablos como paganus o profanus adquieren en la obra de un determinado escritor y, en el caso de profanus, respecto de las transformaciones semánticas que el vocablo experimentó de acuerdo al contexto histórico en que fue empleado incluso por un mismo autor: Van Nuffelen 2011; Beatrice 2005; Beatrice 2010. 
contribuir a profundizar nuestra comprensión del significado que el obispo otorgó al término. En vista de ello, el presente trabajo tiene como objetivo analizar la relación establecida por el autor entre la gentilitas, el peccatum y la bumanitas en el sermón XX.

A tal fin, luego de efectuar unas breves consideraciones respecto de la prédica maximiana en general y sobre el sermón XX en particular, presentaremos el texto latino de la homilía tal como ha sido establecido por Almut Mutzenbecher ${ }^{7}$ junto a nuestra correspondiente traducción. Con tal acción, por otra parte, deseamos comenzar a subsanar la lamentable inexistencia de una traducción de los Sermones al castellano. A continuación, emprenderemos su comentario deteniéndonos particularmente en las secciones que denominaremos "tercera" $\mathrm{y}$ "cuarta", aquellas en las cuales la problemática respecto de la gentilitas no solo se manifiesta más cabalmente, sino que, además, es puesta en relación con el peccatum y con la bumanitas. Llegados a este punto, el recurso a otros sermones del autor contribuirá a la mejor comprensión tanto de la homilía en general como de la cuestión particular que aquí consideramos.

\section{El SERmón XX de MáXimo de Turín}

El sermón XX forma parte de la collectio antiqua, es decir, de la colección de homilías cuya autoría, ya hacia finales del siglo v, se adjudicaba a Máximo ${ }^{8}$. A decir de Mutzenbecher potissimum genuinus Maximi sermo esse uidetur', ya que satisface cuatro de los criterios establecidos por la propia editora para determinar la autoría maximiana de cada una de las homilías $^{10}$ : incluye interpretaciones alegóricas y comparaciones típicas del obispo de Turín, presenta continuidad respecto de otro sermón auténtico y se vale tanto de escritos de Ambrosio de Milán como de los propios sermones de Máximo.

El título con el cual se ha transmitido, Item sequentia, anuncia el desarrollo de la misma temática del sermón XIX al cual, según se asume, este siguió cronológicamente. En efecto, las líneas iniciales del sermón XX aluden a la superior dominica, ocasión en la cual se había comentado Lc.

7. MutZenBeCher 1962, 75-77.

8. MutZenbecher 1962, XXV-XXVI. Respecto de los problemas relativos a la collectio antiqua, ZANGARA 1994, 435-451.

9. MutZenBecher 1962, 74.

10. Para los 16 criterios en base a los cuales Mutzenbecher evaluó la autenticidad de cada uno de los sermones, Mutzenbecher 1961, 202-217. Los mismos criterios se presentan sintéticamente en MutZENBECHER 1962, XXVI-XXIX. 
17, 34 -In illa nocte erunt duo in lecto uno-, debiéndose entonces tratar el versículo siguiente, Erunt duae molentes in pistrino; una adsumetur et una relinquetur (Lc. 17, 35). El sermón XIX, por otra parte, concluía refiriendo al pueblo judío, actor principal de la homilía aquí considerada ${ }^{11}$. Ciertamente, el objetivo de este discurso, pronunciado en lo que con toda probabilidad haya sido una celebración litúrgica ordinaria, se comprende al apreciar la dirección en la cual el orador orientó su exégesis: destacar la superioridad de la Iglesia respecto de la Sinagoga, puesto que solo la primera, según se procuraba demostrar, garantizaba la redención al género humano.

Hasta donde sabemos, el sermón XX ha sido objeto de dos traducciones a lenguas modernas: la primera, al inglés, fue realizada por Boniface Ramsey $^{12}$; la segunda, al italiano, por Gabriele Banterle ${ }^{13}$. Filippo Gallesio ${ }^{14}$, Luigi Padovese ${ }^{15}$, Nadine Plazanet-Siarri ${ }^{16}$ y Milena Mariani Puerari ${ }^{17}$ no incluyeron esta homilía en sus respectivas traducciones parciales de los Sermones.

Tanto Mutzenbecher como Ramsey y Banterle han notado las semejanzas existentes entre el comentario de Máximo y aquel realizado respecto del mismo versículo evangélico por Ambrosio de Milán en su Expositio Evangelii secundum Lucam $^{18}$ VIII, 48 y 52. En tanto que Mutzenbecher ${ }^{19}$ y Banterle ${ }^{20}$ se limitaron a indicar la necesidad de confrontar los textos, Ramsey fue algo más allá al señalar la existencia de cierta dependencia ${ }^{21}$. Entendemos que no es esta una cuestión menor, ya que de la libertad o, por el contrario, de la sumisión que Máximo hubiese exhibido ante la autoridad del texto ambrosiano depende nuestra posibilidad de acceder al pensamiento genuino del obispo de Turín.

11. S. XIX, 81-86.

12. Ramsey 1989 , 49-51 y notas en las páginas 286-287.

13. Banterle 1991, 101-105 (la traducción es reproducida en Banterle, Petri 2003, 100103).

14. Gallesio 1975.

15. PADOVESE 1985.

16. Hamman, Plazanet-Siarri 1996.

17. Mariani Puerari 1999.

18. Seguimos en todos los casos la edición de Adriaen 1957. En adelante Exp. Luc.

19. " $7 / 10$ cf. Ambr. in Luc. 8, 48»; «24/28 cf. Ambr. in Luc. 8, 48»; «61/69 cf. Ambr. in Luc. 8, 52»; «77/81 cf. Ambr. in Luc. 8, 52", MutzenBecher 1962, respectivamente en las páginas 75 (los dos primeros casos), 76 y 77.

20. "Cf. Ambr., In Lc., 8, 48"; "Cf. Ambr., In Lc., 8, 52", BANTERLE 1991, respectivamente en las páginas 101, nota 2 y 103 , nota 4 .

21. "The imagery of the millstones and of the women who are grinding seems to depend on Ambrose, Exp. evang. sec. Luc. 8.48 and 52» (RAmsey 1989, 286, nota 1). 
Las similitudes entre ambos comentarios son innegables. En efecto, en uno y otro las dos mujeres que muelen eran figura respectivamente de la Iglesia y de la Sinagoga ${ }^{22}$, aunque ni en la Expositio ni en el resto de la obra ambrosiana es esta la única interpretación realizada ${ }^{23}$. Es incluso cierto que algunas expresiones del sermón XX y de la Expositio guardan similitud textual ${ }^{24}$. Resulta factible, pues, que Máximo no solo se haya

22. Exp. Luc. VIII, 48, 534-543: «Luego, en este molino, [ya sea] la Sinagoga o el alma sometida a los pecados, ha de molerse un trigo humedecido. Corrompido por una humedad excesiva, no se puede separar lo interior de lo exterior, y por esto será dejado, porque su harina resulta desagradable. Por el contrario, la santa Iglesia o el alma no manchada por el contacto con los pecados, la cual muele un trigo tal que está seco al calor del sol eterno, un trigo al que dios revistió del modo que quiso y los ángeles limpiaron de toda mancha de inmundicia, da valor a la ofrenda de su sacrificio presentando a dios buena harina desde lo más interior del hombre" (In hoc ergo pistrino uel synagoga ue1 anima obnoxia delictis triticum molendo madefactum et graui umore corruptum non potest interiora ab exterioribus separare et ideo relinquetur, quia eius similago displicuit. At uero sancta ecclesia uel anima nullis maculata contagiis delictorum, quae tale triticum molit, quod solis aeterni calore sit torridum, quod deus quemadmodum uoluit sic uestiuit et angeli ab omni purgamentorum labe mundarunt, bonam similaginem de penetralibus hominum deo offerens sacrificii sui libamenta conmendat). Poco después, insistía, "Así, aquellas dos que muelen [son] dos almas o la Iglesia y la Sinagoga” (Exp. Luc. VIII, 52, 610-612: Duae autem illae molentes duae animae uel certe ecclesia atque synagoga). Del mismo modo interpretaba Ambrosio el versículo evangélico en cuestión en su De Cain et Abel, I, 8, 30, 12-15. En efecto, refiriéndose a la harina espiritual (similago spiritalis) ofrecida por Abraham a Dios cuando este se había aparecido ante él junto a la encina de Mambré de acuerdo al relato de Gen. 18, 1-8, señalaba: «Esta es la harina que en el Evangelio muele aquella mujer que será tomada; una será tomada, dice, la otra será dejada. Será tomada la Iglesia, será dejada la Sinagoga; o si se quiere, será tomada el alma buena, será dejada el alma malvada" (haec est similago, quam in euangelio molit illa mulier, quae adsumetur; una enim adsumetur inquit altera relinquetur. adsumetur ecclesia, relinquetur synagoga uel mens bona adsumetur, inproba derelinquetur. En SCHENKL1896).

23. Como se ve en la nota previa, a decir de Ambrosio las dos mujeres que molían eran no solo figura de la Iglesia y de la Sinagoga, sino también de dos tipos de almas. Otra lectura alternativa se aprecia en su De paenitentia, I, 15, 82, 41-49: "Pues esta levadura -es decir, la doctrina de los fariseos y la controversia de los saduceos- ocultó la Iglesia en su harina cuando suavizó con la interpretación espiritual la más dura letra de la Ley y, por así decirlo, quebró con una cierta muela de molino sus controversias, haciendo salir de la envoltura de las letras los secretos interiores de los misterios y añadiendo la fe en la resurrección, por la cual es predicada la misericordia de Dios y por la cual se cree que es restablecida la vida de los difuntos" (Hoc ergo fermentum, hoc est doctrinam Pharisaeorum et disputationem Sadducaeorum abscondit Ecclesia in farina sua, cum litteram legis duriorem spiritali interpraetatione mollivit et velut mola quadam suae disputationis infregit, proferens velut de folliculis litterarum mysteriorum interna secreta et resurrectionis fidem adstruens, qua Dei misericordia praedicatur, qua reparari vita creditur mortuorum. En FaLLer 1955).

24. Valgan dos ejemplos: 1) Exp. Luc. VIII, 48, 530-531: Discutiamus ergo quae molant quidue molant quidue pistrinus sit; S. XX, 8-10: Primum igitur considerandum est, 
inspirado en el escrito de su par de Milán, sino también que lo haya tenido ante sí al momento de elaborar el propio. Sin embargo, debe señalarse que, tanto en el conjunto de su obra homilética como en este sermón en particular, el obispo de Turín se valió de los escritos de Ambrosio sin ceñirse a su contenido ni a sus interpretaciones. Por el contrario, se apartó de aquellos lo suficiente como para proponer lecturas radicalmente distintas de unos mismos versículos evangélicos ${ }^{25}$. En tal sentido, compartimos plenamente la afirmación de Federico Trisoglio cuando señala que "Dai luoghi convergenti risulta che Massimo non rifiuta i suggerimenti che ritiene valevoli, li accetta, ma senza lasciarsene dominare; sa appropriarseli e camminare in proprio ${ }^{26}$.

Por lo que ahora nos interesa, es necesario indicar que en los pasajes señalados de la Expositio no se hacía referencia alguna a los elementos que, como veremos, resultan fundamentales para la exégesis realizada por Máximo en su sermón XX. Ciertamente, no se aludía allí ni a las dos piedras, ni a sus características particulares, ni a la superioridad de una sobre otra. Más importante aún, ni la gentilitas ni la bumanitas $^{27}$ ni el peccatum respecto del cual -como veremos- trataba aquí Máximo se hallaban presentes en el comentario de Ambrosio. La lectura alegórica contenida en la homilía que aquí consideramos, al igual que la asociación establecida entre estos fenómenos, son, pues, expresión cabal del pensamiento maximiano.

Hemos distinguido 5 secciones al interior de la homilía: I) preámbulo; II) la molienda secular; III) interpretación alegórica: las dos piedras y los dos testamentos; IV) la «molienda eclesiástica»; V) confrontación de la Iglesia y la Sinagoga. En torno a ellas estructuraremos el análisis del sermón una vez presentados el texto latino y nuestra traducción.

quomodo constet molentis officium, deinde quae sunt duae quae molere dicuntur, tertio quod pistrinum sit quiue molitionis effectus; 2) Exp. Luc. VIII, 48, 542-543: ... bonam similaginem de penetralibus hominum deo offerens sacrificii sui libamenta conmendat; S. XX, 63-69: ... et caelestibus mandatis mundata ex intimis spiritalia alimenta producat [...] ac spiritum nostrum omni humanitate purificans uelut similaginem deo offerre contendit...

25. Un buen testimonio de ello se aprecia en S. XLVIII. Al respecto, véase Noce 2019a, 183-191.

26. Trisoglio 2001, 633. Ya Mutzenbecher se había expresado de similar modo en MutZENBECHER 1961, 214-216.

27. El sentido con el cual se emplea el término humanus en Exp. Luc. VIII, 48, 531533 (Et fortasse mundus iste pistrinum sit, in quo aptius reor quia humani corporis forma referatur...) es completamente diferente de aquel que, como veremos, corresponde a humanitas en el sermón XX del obispo de Turín. 
3. TeXto latino y traduCCIÓN ${ }^{28}$

\section{XX. \\ ITEM SEQVENTIA}

I. (1) Superiore dominica capitulum euangelicum disserentes partem quandam ex illo perstrinximus; (2) superest ut sequentia decurramus. (3) Descripsimus enim quid esset quod ait dominus: In illa nocte erunt duo in lecto uno et reliqua. (4) Nunc ergo uideamus quod reliquum est! (5) Dicit enim eadem diuina sententia: Erunt duae molentes in pistrino; una adsumetur et una relinquetur. (6) Primum igitur considerandum est, quomodo constet molentis officium, deinde quae sunt duae quae molere dicuntur, tertio quod pistrinum sit quiue molitionis effectus.

II. (1) Nulli dubium est quod molere aliter non constat nisi duobus lapidibus adparatis et conuenientibus sibi, ut alteri ex his magnitudo alterius inponatur; (2) et illum quidem lapidem qui prior solo sternitur esse pigrum et tardum et paene, ut ita dixerim, otiosum; (3) ac nisi superioris participatione lapidis ornaretur, forsitan necessarius non uideretur. (4) Ita dum ille operatur, etiam iste utilis inuenitur. (5) Ille autem, id est superior lapis, tanta uelocitate operis circumfertur, ut fallens oculos in ipsa celeritate stare credatur, et putetur inmobilis esse dum currat. (6) Qui quanto uiolentius actus fuerit, tanto opus perfectius consummatur. (7) Ita ergo prior lapis stat iacet et paene nihil prodest, (8) ille uero alter quae inferuntur cuncta suscipit, quae ueniunt uniuersa conplectitur; (9) et per cauernulas quasdam uterque quod operetur adquirit. (10) Qui molit autem hoc habere uidetur officii, ut peruigili cura granorum asperitate confracta ex intimis eorum occultisque uisceribus similaginem medullamque producat; (11) et sordium leuitate discussa in apertum profert omne quod purum est, (12) ex quo mundissimum panem conficiens gratiam domini consequatur.

III. (1) Hos igitur duo molares lapides duo esse arbitror testamenta, hoc est legem Mosi et euangelium domini, quae ita sunt disposita uel parata, ut sibi testamentum utrumque conueniat, sicut ait saluator: Non veni legem soluere sed adimplere; (2) et ad uicem molarum aliud prius solo positum aliud insuper collocatum, hoc est legem primum hominibus constitutam, deinde ad perfectum euangelium confirmatam. (3) Quae lex uelut inferius molare saxum ita erat tarda pigra et paenitus otiosa, ut quidquid operando acceperat, id omne perdiderit dicente de Iudaeis propheta: Omnes

28. La numeración de los párrafos sigue la del texto editado por Mutzenbecher. Se condice, además, con la estructura que hemos establecido anteriormente para este sermón. Los números entre paréntesis al interior de cada uno de ellos han sido añadidos ad hoc con la intención de simplificar las referencias al momento de realizar el análisis de la homilía. 
declinauerunt, simul inutiles facti sunt; non est qui faciat bonum, non est usque ad unum. (4) Ergo nisi euangelium superpositum fuisset, adhuc lex ueluti tarda et grauis iaceret in terra Iudaica, et unius prouinciae cooperiretur angustiis. (5) Nisi euangelium, inquam, datum esset, lex necessaria omnino non esset. (6) Hoc autem lex operabatur sine euangelio, quod uno saxo fieri potest. (7) Confringere poterat non prodesse, sicut ait beatus apostolus: Lex autem iram operatur; gratiam uero non praestat. (8) Stante ergo lege euangelium datum est, quod ueteri superpositum testamento utrumque condecorat; (9) ac tanta uelocitate operis circumfertur, ut uolubilitate sui saeculum omne circumeat, hoc est inferna uisitet caelestia penetret terrena conlustret. (10) Quod euangelium tamquam superior mola cunctos credentes suscipit, omnes aduenientes accipit (11) et ueluti per quasdam cauernulas praeceptorum ad interiora transmittit, uti hinc inde (12) duorum testamentorum salutaribus mandatis (13) gentilitatis asperitate mollita (14) producat omne quod purum est. (15) Quam similitudinem testamentorum Hezechielem prophetam arbitror perstrinxisse, cum dicit rotam in medio rotae esse conexam.

IV. (1) Harum igitur molarum operatione, id est noui ac ueteris testamenti, hoc agit sancta ecclesia cura peruigili, (2) ut peccatorum asperitate discussa (3) ex occultis cogitationibus medullam mundi cordis eliceat; (4) et caelestibus mandatis mundata (5) ex intimis spiritalia alimenta producat (6) -de quibus alimentis Paulus apostolus ait: Lac uobis potum dedi non escam; et iterum: Perfectorum autem est solida esca, qui propter habitum sensus exercitatos habent et reliqua- (7) ac spiritum nostrum omni humanitate purificans (8) uelut similaginem deo offerre contendit, (9) sicut Dauid sanctus ait: Sacrificium deo spiritus contribulatus. (10) Tanta autem uelocitate circumfertur euangelium, ut nonnisi sapientes cursum eius intellegant, quem beatus Paulus intellegens ait: Vt sermo dei currat et clarificetur in nobis. (11) Insipientium autem oculis uidetur euangelium stare, cum non uident. (12) Stare, inquam, illud putant, cum mandata eius neglegunt, cum non credunt euentura esse quae scripta sunt.

V. (1) Molit autem et synagoga sed inutiliter molit, quippe quae uno saxo, hoc est solo ueteri testamento, nititur laborare; atque ideo non tam molit illa quam dissipat et confringit. (2) Propterea enim opus eius displicet et ad Iudaeos dicitur per prophetam: Et si adferatis similaginem, uanum est; (3) et ipse dominus reprobans operationis eius officium ait: Cauete uobis a fermento Pharisaeorum. (4) Conatur igitur Synagoga molere errorem sustinens. (5) Etenim quia Moyses duas lapideas tabulas acceperat testamenti, aestimat se duobus instrumentis necessariis operari, ignorans quod illa tabularum societas duorum testamentorum cohaerentium sibi praefigurabat aduentum. (6) Atque ideo assumetur in aeternam gloriam sancta ecclesia, quae domino cibum sanctitatis emolit; (7) relinquetur ad molas cruenta synagoga gyrum semper suae passura perfidiae. 


\section{XX. SOBRE EL MISMO TEMA}

I. (1) El domingo pasado, tratando un capítulo del Evangelio, tocamos brevemente una parte. (2) Falta que consideremos lo demás. (3) Explicamos, en efecto, lo que dijo el Señor: En aquella noche habrá dos en un lecho y lo que sigue. (4) Veamos ahora, pues, el resto. (5) Dice la misma sentencia divina: Habrá dos moliendo en el molino. Una será tomada; la otra será dejada. (6) Lo primero que debe ser considerado es de qué modo se comprende el oficio de quien muele; luego quiénes son las dos de quienes se dice que muelen; en tercer lugar qué es el molino y cuál el efecto de la molienda.

II. (1) No hay dudas de que el moler no se realiza de otro modo sino con dos piedras preparadas y convenientes entre sí para que, según sea el tamaño de la una, se imponga el de la otra. (2) Y ciertamente, aquella primera piedra que se coloca en el fondo es inactiva, lenta y, por así decirlo, completamente ociosa. (3) Y si no fuese dispuesta la participación de la piedra superior, quizá no se la consideraría necesaria. (4) Así, mientras aquella trabaja, también esta se muestra útil. (5) Por su parte, aquella -es decir, la piedra superior-, gira con tanta velocidad en su trabajo que, engañando a los ojos, se cree que aun a tanta velocidad está quieta y se piensa que está inmóvil mientras corre. (6) Cuanto más impetuoso sea el movimiento, más perfectamente se realiza el trabajo. (7) Así pues, esta primera piedra está inmóvil, yace y casi para nada sirve; (8) aquella otra verdaderamente admite todo lo que es echado, recibe todo lo que llega, (9) y como por unas pequeñas cavidades la una y la otra se procuran el objeto de su trabajo. (10) Efectivamente, quien muele parece tener este deber: con diligente cuidado, una vez destruida la aspereza de los granos, hacer salir de sus íntimas y ocultas entrañas la flor de la harina y el tuétano; (11) apartada la futilidad de las suciedades, revelar todo lo que es puro, (12) con lo cual, preparando el pan purísimo, alcanza el favor del señor.

III. (1) Pues bien, considero que estas dos piedras de moler son los testamentos, esto es, la ley de Moisés y el Evangelio del Señor, los cuales están ordenados y dispuestos de tal modo que uno y otro estén de acuerdo entre sí, como dice el Salvador: No vine a abolir la ley, sino a cumplirla. (2) Y como en el caso de las piedras, el primero está puesto en el suelo y el otro es colocado encima; es decir, establecida primero la ley para los hombres, luego fue confirmada en acuerdo con el Evangelio consumado. (3) Esta ley, como la piedra de moler inferior, era hasta tal punto lenta, inactiva y completamente ociosa, que todo lo que recibía para ser trabajado se echaba a perder, como dice el profeta respecto de los judíos: 
Todos se desviaron, y al mismo tiempo se han vuelto inútiles; no hay quien haga el bien, no bay ni siquiera uno. (4) Así pues, si el Evangelio no hubiese sido colocado encima, por así decirlo, todavía la ley yacería lenta y pesada en tierra judía, y estaría oculta en la estrechez de una única provincia. (5) Y si no hubiese sido dado el Evangelio, digo, la ley no sería en verdad necesaria. (6). Efectivamente, trabajando sin el Evangelio la ley podía hacer lo que se hace con una sola piedra. (7) Podía romper, pero no podía ser útil, como dice el santo apóstol: En efecto, la ley produce ira; en verdad, no proporciona la gracia. (8) Luego, estando inmóvil la ley, fue dado el Evangelio, el cual, superpuesto al viejo testamento, embellece uno y otro. (9) Y se lo hace girar con tanta velocidad en su trabajo para que con su giro recorra todo el siglo, es decir, visite los infiernos, penetre en los cielos y recorra los territorios terrestres. (10) Este Evangelio, como la piedra superior del molino, recibe a todos los creyentes, acepta a todos los que llegan (11) y, como a través de las pequeñas cavidades de los preceptos, los hace pasar hacia las partes interiores, de modo que a partir de aquí, (13) suavizada la aspereza de la gentilidad (12) entre los preceptos salvadores de los dos testamentos, (14) haga salir todo lo que es puro. (15) Pienso que el profeta Ezequiel consideró brevemente esta imagen de los testamentos cuando dijo que una rueda está en el medio de una rueda.

IV. (1) Con el trabajo de estas muelas, es decir, del Nuevo y del Viejo Testamento, con atento cuidado la santa Iglesia realiza esto: (2) apartada la aspereza de los pecados, (3) de los pensamientos ocultos extrae el tuétano de un corazón limpio; (4) y, lavado por los mandatos celestiales, (5) hace salir de lo íntimo alimentos espirituales (6) -de los que el apóstol Pablo dice: Les di leche para beber, no comida; y otra vez: El alimento sólido es para los perfectos, quienes a causa de su condición tienen sus facultades entrenadas, y lo que sigue- (7) y purificando nuestro espíritu de toda condición humana, (8) busca presentarlo a Dios como flor de harina, (9) como dice el santo David: El espiritu humillado es un sacrificio para Dios. (10) Ahora bien, el Evangelio es hecho girar con tanta velocidad que solamente los sabios comprenden su curso, entendiendo lo cual dijo el santo Pablo: Para que la palabra de Dios corra y sea glorificada en nosotros. (11) Sin embargo, a los ojos de los necios el Evangelio parece estar inmóvil, cuando no ven. (12) Inmóvil, digo, piensan que está, cuando desprecian sus mandatos, cuando no creen que sucederá lo que está escrito.

V. (1) Así pues, muele también la Sinagoga, pero muele inútilmente, puesto que se empeña en trabajar con una única piedra, esto es, únicamente con el viejo testamento, y por eso no muele tanto como disipa y rompe. (2) Por esta razón, pues, su obra resulta desagradable, y se dice a 
los judíos a través del profeta: Incluso si trajeras flor de harina, sería vano. (3) Y el mismo Señor, reprobando su actividad, dice: Cuidaos del fermento de los fariseos. (4) Así, la Sinagoga, conservando su error, intenta moler. (5) Verdaderamente, puesto que Moisés había recibido las dos tablas de piedra de los testamentos, consideró que obraba con los dos instrumentos necesarios, ignorando que aquella concordia de las tablas prefiguraba la llegada de los dos testamentos, que forman entre sí un todo. (6) Y por esto será adoptada en la gloria eterna la santa Iglesia, que muele para el Señor alimento de santidad; (7) será dejada en las piedras de moler la Sinagoga ensangrentada, para que sufra siempre el giro de su perfidia.

\section{ANÁLISIS DEL SERMÓN}

\subsection{Sección I: preámbulo}

El preámbulo consta de dos partes. La primera de ellas (I, 1-5 = S. XX, 2-8) evidencia la continuidad temática y cronológica de este sermón respecto de aquel que lo antecede en la edición de Mutzenbecher. En efecto, como hemos dicho, señalaba allí Máximo que superior dominica se había tratado sobre el pasaje evangélico In illa nocte erunt duo in lecto uno (Lc. 17, 34), debiéndose en la ocasión presente abordar su continuación: Erunt duae molentes in pistrino (Lc. 17, 35). En la segunda (I, $6=\mathrm{S} . \mathrm{XX}$, 8-10), en tanto, el autor anticipaba a su auditorio el objetivo del comentario exegético a realizar: comprender el funcionamiento y finalidad de la molienda e identificar las entidades figuradas en el propio molino y en las mujeres que en él trabajaban.

\subsection{Sección 2: la molienda secular}

Las palabras con las cuales Máximo comenzaba esta sección de su discurso, Nulli dubius est (II, $1=\mathrm{S}$. XX, 11), presentaban como evidente e incuestionable ante su auditorio cuanto el orador habría de señalar a continuación respecto del proceso de molienda, esto es, de la composición del molino, de su mecánica y de su finalidad. Con ello el orador legitimaba los términos en torno a los cuales, de acuerdo a sus objetivos, habría de estructurarse su interpretación alegórica en el apartado siguiente.

Su exposición reducía el procedimiento de la molienda a lo esencial. Insistía, en primer lugar, en la necesidad de dos piedras que, situadas una sobre la otra, se complementasen (II, $1=\mathrm{S}$. XX, 11-13). Luego, destacaba la desigual importancia que a cada una de ellas correspondía para 
la realización de la tarea: la piedra inferior, en efecto, no solo era caracterizada como pigrum, tardum y paene otiosum (II, 2 = S. XX, 13-15), sino que, permaneciendo quieta, yaciendo y siendo por sí misma inútil (II, 7 $=\mathrm{S}$. XX, 21-22), únicamente resultaba provechosa en presencia de la piedra superior (II, 3-4 = S. XX, 15-17); esta, en tanto, girando velozmente -puesto que a mayor velocidad más eficaz resultaba el trabajo (II, 5-6 = S. XX, 17-21)-, recibía la materia a procesar (II, $8=\mathrm{S}$. XX, 22-23) a través de unas cauernulae (II, $9=\mathrm{S}$. XX, 23-24).

A continuación realizaba dos consideraciones de carácter general. Primero, aseveraba que el objetivo de quien molía era doble: por un lado, destruir la asperitas de los granos; por otro, hecho esto con diligente cuidado, hacer salir ex intimis eorum occultisque uisceribus la flor de harina y el tuétano (II, $10=$ S. XX, 24-27). De inmediato reiteraba la misma idea, aunque esta vez en términos algo más abstractos: en efecto, refería ahora a la eliminación de la suciedad de los granos y a la revelación de todo lo puro contenido en su interior (II, $11=\mathrm{S}$. XX, 27-28). Con esto, entendemos, daba inicio a la transición que conducía desde la molienda material hacia la "molienda espiritual». Concluía esta sección indicando la finalidad primordial del acto de moler: preparar el mundissimum panem con el cual su artífice se hacía digno del favor de su señor (II, 12 = S. XX, 28-29).

\subsection{Sección 3: interpretación alegórica. Las dos piedras $y$ los dos testamentos}

Desplegaba ahora Máximo su lectura alegórica del proceso anteriormente descrito. Consideraba que las dos piedras eran imagen de los dos testamentos, a saber, legem Mosi et euangelium domini, uno y otro en todo de acuerdo entre sí (III, 1 = S. XX, 30-34). Como aquellas, estos estaban dispuestos uno sobre el otro, ya que la Ley, dada en primer lugar, había sido luego confirmada por el Evangelio (III, 2 = S. XX, 34-36). Aquella, al igual que la piedra inferior, era calificada como tarda, pigra y paenitus otiosa (III, 3 = S. XX, 36-41), características que aún conservaría, señalaba el autor, si no hubiese sido dado a los hombres el Evangelio (III, 4-5; S. $\mathrm{XX}, 41-44)$. Sin este, como un molino que operase con una sola piedra, el trabajo de la Ley no resultaría provechoso, ya que lo único que podía hacer por sí sola era romper el grano (III, 6-7; S. XX, 44-47). La superposición del euangelium había redundado en el embellecimiento de ambas piedras (III, $8=\mathrm{S}$. XX, 47-49). Puesto que -como se había dicho en II, 5-6 $=\mathrm{S}$. XX, 17-20-, a mayor velocidad de acción mejor resultaba la labor, el Evangelio era hecho girar al máximo de sus posibilidades, alcanzando de este modo cielo, tierra e infierno (III, $9=\mathrm{S}$. XX, 49-51). 
Llegamos así a las líneas a nuestros fines más importantes de este sermón, aquellas contenidas entre III, 10 y IV, 8 (= S. XX, 52-69). En efecto, en III, 10-14 (S. XX. 52-59) Máximo exponía el funcionamiento y el objetivo de la molienda -ya no material sino espiritual- realizada a partir de la acción conjunta de los dos testamentos. El Evangelio, en tanto que "piedra superior", recibía como grano a omnes aduenientes, denominados ahora credentes (III, $10=\mathrm{S}$. XX, 52-53). A través de las cauernulae praeceptorum estos eran conducidos hacia el interior del molino (III, $11=\mathrm{S}$. XX, 53-55), donde, por la acción conjunta de los saluatoria mandata de los dos testamentos (III, $12=\mathrm{S}$. XX, 54-55), era suavizada en ellos la gentilitatis asperitas (III, $13=\mathrm{S}$. XX, 55-56), permitiendo la obtención de omne quod purum est (III, $14=\mathrm{S}$. XX, 56).

Se presenta en estas líneas, pues, la única alusión a la gentilitas contenida en el sermón XX. De acuerdo a Máximo, se trataba de un elemento que, presente en quienes se acercaban al Evangelio -esto es, a la Iglesia, según veremos de inmediato-, debía ser suavizado a través del sometimiento de tales sujetos a los preceptos y mandatos testamentarios. La realización de tal acción permitía liberar el componente puro en ellos contenido.

Antes de abordar la sección crucial de la homilía, deben destacarse dos circunstancias: por un lado, la asociación establecida por el autor entre gentilitas y asperitas $^{29}$ y entre gentilitas y mandata-praecepta-obseruationes $^{30}$; por otro, la certeza de que el individuo podía ser liberado de su gentilitas ${ }^{31}$. Una y otra consideración reaparecen en distintos sermones en que la cuestión gentil se hace presente, hecho que da cuenta de una concepción coherente, homogénea y sólidamente construida de la gentilitas por parte del obispo de Turín.

29. Asociaciones de los gentiles con la asperitas: S. XX, 55-56, 61-63; S. XXXIII, 83-84; S. LXXXVIII, 49-55.

30. Alusiones a la purificación de los gentiles a través del sometimiento a los praecepta, mandata y obseruationes: S. XX, 53-56 (praecepta, mandata), 63-64 (mandata); S. XXXV, 9-10 (praecepta), 69-72 (mandata, obseruationes).

31. Son muy numerosos los pasajes de los Sermones que permiten advertir la confianza del orador en la redención de los gentiles, ya sea que proyecten su paso a la fe hacia el futuro o que refieran al pasado gentil de los integrantes del auditorio. Al respecto, véase $\mathrm{S}$. II, 54-56; S. XX, 52-69; S. XXXIII, 82-85; S. XXXV, 82-89; S. XLVIII, 93-94; S. LXIc extr., 65-72; S. LXXIII, 46-50; S. LXXXIV, 87-93; S. XCI extr., 37-39; S. XCVIII extr., 11-20; S. CIII extr., 20-29; S. CV extr., 49-51; S. CVI extr., 20-21. 


\subsection{Sección 4: la molienda eclesiástica}

Al comienzo mismo de la cuarta sección de la homilía se identificaba el ámbito en el cual la "molienda espiritual» era efectuada: la ecclesia. Se consumaba así la transición desde la molienda mundana realizada por las mujeres, con sus efectos sobre la materia, a la "molienda eclesiástica» operada por la Iglesia, con sus resultados sobre el spiritus. La posesión de las dos piedras requeridas para la tarea, esto es, noui ac ueteris testamenti, garantizaba a esta la efectividad de la labor que -como la molinera- realizaba cura peruigili (IV, $1=$ S. XX, 60-61).

Resulta evidente que la molienda atribuida a la acción de los dos testamentos en las líneas finales de la tercera sección coincide con la "molienda eclesiástica» narrada al comienzo de la que ahora consideramos. Lo que Máximo deseaba destacar llegado a este punto era que únicamente la Iglesia podía dar curso con éxito a tal empresa puesto que solo ella operaba con los dos testamentos. No es esta una cuestión menor si se tiene en cuenta que, como se dijo, el sermón constituía un elogio de la Iglesia en confrontación con la Sinagoga. Sin embargo, lo que ahora nos interesa destacar es la existencia de una evidente relación entre la gentilitas, el peccatum y la bumanitas. Así lo sugiere el hecho de que todas estas características fueron presentadas por Máximo como elementos cuya erradicación resultaba crucial para la concreción del objetivo del proceso de molienda: solo «suavizada la aspereza de la gentilidad» resultaba posible obtener "todo lo que es puro" (III, 13-14 = S. XX, 54-56); una vez "apartada la aspereza de los pecados", se extraía "de los pensamientos ocultos el tuétano de un corazón limpio» (IV, 2-3 = S. XX, 61-63); al purificar "nuestro espíritu de toda condición humana", este era digno de ser presentado «a Dios como flor de harina" (IV, 7-8 = S. XX, 67-69). Ahora bien, nuestro conocimiento respecto del significado que a gentilitas correspondió en la prédica maximiana resultará sin duda profundizado en caso de que podamos determinar a qué peccatum hacía referencia el orador en esta ocasión, qué entendía por humanitas y cómo se relacionaban entre sí estos elementos.

Ciertamente, Máximo exigía en esta homilía que «la aspereza de los pecados» (IV, 2 = S. XX, 61-62: ut peccatorum asperitate discussa) fuese removida para que resultase posible extraer el tuétano de un corazón limpio. Sería necio obviar que se empleó el genitivo plural -y no el singular- de peccatum. Sin embargo, según veremos a continuación, el autor asociaba un pecado en particular con la condición de gentilitas y era este, entendemos, el que debía erradicarse. El empleo de la forma plural, sugerimos de manera hipotética, bien pudo deberse al hecho de que las 
restantes transgresiones cometidas por el individuo resultaban, en definitiva, consecuencia de aquel.

La especificidad de tal peccatum se percibe acudiendo a otras homilías del autor. En el sermón XLIII afirmaba Máximo que, al comer el fruto del árbol prohibido, Adán "renunció a la savia de la inmortalidad; y, en aquel momento, en cierto modo se resecó, cuando con su pecado hizo que el hombre hecho a imagen de Dios se disolviese en el polvo ${ }^{32}$. Pero si el pecado de Adán había sido la causa del inicio de una condición humana degradada, esta situación era revertida durante la Cuaresma. En aquel tiempo, según se afirmaba en el sermón CXI extr., junto al perdón se concedía al individuo su plenitud originaria. En efecto, se señalaba que mediante la observancia de la Cuaresma se persigue un cierto restablecimiento del género humano, y que en este tiempo, el más sagrado, es renovada la fragilidad de nuestra condición. Es renovada, en efecto, nuestra fragilidad cuando Cristo, perdonando, restituye la gracia de la inmortalidad que Adán había perdido cometiendo una falta ${ }^{33}$.

Tres circunstancias merecen ser destacadas en estos pasajes: por un lado, la asociación, común a ambos, del pecado de Adán con el comienzo de una nueva y deteriorada etapa en la historia espiritual del género humano, signada por la fragilidad, la muerte, la sequedad; por otro, la puesta en relación del individuo que en esta condición se encontraba con la siccitas, rasgo atribuido a los gentiles también en el sermón $\mathrm{XXXV}^{34}$; por último, el hecho de que tal condición pudiese ser revertida, a decir del orador, por la intervención de Cristo: cum inmortalitatis gratiam [...] Christus indulgendo restituat.

Las alusiones a la penosa condición del hombre, a la siccitas y a lo que estaba perdido pero podía y debía recuperarse a través de la intervención divina nos conducen a afirmar que el estado en que se ingresaba a causa del pecado de Adán y que se superaba con el bautismo no era otro que el de gentilitas. El autor, pues, aludía en los pasajes recién evocados, como en tantas otras homilías ${ }^{35}$, al mismo proceso de redención

32. S. XLIII, 58-60: ... sucum inmortalitatis amisit; et tunc siccata quodammodo est, quando bominem ad imaginem dei factum peccato suo solui fecit in puluerem.

33. S. CXI extr., 3-7: ... reparatio quaedam humani generis agitetur, et quod per hoc sacratissimum tempus condicionis nostrae fragilitas innouatur. Innouatur enim nostra fragilitas, cum inmortalitatis gratiam, quam Adam delinquendo perdiderat, Christus indulgendo restituat.

34. S. XXXV, 85-89. En similar sentido, como hemos dicho, Máximo asociaba reiteradamente a los gentiles con la asperitas (véase la nota 29).

35. Muy significativos al respecto resultan, entre otros, los sermones XXXIII, XXXV, LV, LXV y CIII extr. 
humana que en el sermón XX era abordado mediante la imagen de la "molienda eclesiástica" ante la necesidad de comentar la lectura del día ${ }^{36}$. De este modo, los sermones XLIII y CXI extr. nos permiten comprender la razón de ser de la caída y permanencia del hombre en aquel -a decir de Máximo- lamentable estado de gentilitas: el peccatum de Adán había afectado la perfección originaria del espíritu humano, arrancando al hombre de su condición primigenia, denominada por Máximo ad imaginem dei en su ya evocado sermón XLIII y secundum deum en el sermón LV:

La renovación, en efecto, consiste en que dejes lo que eras y asumas lo que anteriormente habías sido. Renovación, digo, es -y también por esto son llamados neófitos- que hayan echado de sí las máculas de lo viejo por medio de una cierta transformación, que hayan adoptado la gracia de la sencillez, como dice el Apóstol: Quitándose de encima al hombre viejo junto con sus actos, recubríos del hombre nuevo, que ha sido creado a imagen de Dios $^{37}$.

La centralidad que asumió en la prédica del obispo de Turín esta evolución hacia el pasado, este retorno del hombre desde la gentilitas hacia el estadio secundum Deum se manifiesta como en ningún otro pasaje de su obra en la continuidad del sermón CXI extr., donde se aseveraba que tal transformación constituía el objetivo mismo del cristianismo:

En efecto, esta es la razón de ser del cristianismo y de la fe, que se salve lo que se había perdido, que se vuelva a llamar lo que se había extraviado, que renazca lo que había muerto. «Renazca nuevamente», digo, no «nazca $»^{38}$.

Establecida así la relación existente entre gentilitas y peccatum, debemos preguntarnos a continuación de qué manera la bumanitas se articulaba con dichos fenómenos. Comencemos examinando el modo en que el obispo empleó dicho término en sus Sermones. Humanitas emerge 5 veces en un total de 4 homilías entre aquellas consideradas auténticas o

36. La "molienda eclesiástica» reaparece en S. XXXIII, 77-89, pasaje en que Máximo alude nuevamente, en este caso de modo breve, al pasaje relativo a los dos mujeres que muelen en el molino.

37. S. LV, 6-12: ... innouatio enim quaedam est desinere quod eras, adsumere ante quod fueras. Innouatio, inquam, est, unde et neofyti nuncupantur, quod nouitate quadam maculas uetustatis abiecerint, gratiam simplicitatis adsumpserint dicente apostolo: Deponentes ueterem hominem cum actibus eius induite nouum, qui secundum deum creatus est.

38. S. CXI extr., 9-12: Nam haec est omnis causa christianitatis et fidei, ut saluetur quod perierat reuocetur quod errauerat quod iam occiderat renascatur. 'Renascatur, inquam, denuo' non 'nascatur'. 
dudosas por Mutzenbecher ${ }^{39}$. En tres casos -dos de ellos contenidos en el sermón XXI y el restante en el LXXII- se utilizó para dar cuenta de un acto que reunía las dos características siguientes: por un lado, se realizaba en beneficio de un tercero, es decir, contenía una dimensión altruista; por otro, quien ejecutaba la acción lo hacía movido por el afecto. En atención a ello, parece correcto traducirlo por "amabilidad" o "cordialidad»:

Por esta razón, pues, se apresuró Abraham a recibir a los hombres santos, para merecer participar de su santidad al hacerlos partícipes de su hospitalidad. Y mientras pone en común la disposición de su amabilidad, recibe la participación en la santidad ${ }^{40}$.

¿Quién no querría recibir en tales condiciones a un santo en la cordialidad de su tienda para, siendo partícipe con este de la morada, hacerse partícipe de la santidad? ${ }^{?+1}$.

Dime, si das a alguien algo de lo que es tuyo, ¿no esperas que te agradezca, que bendiga el hogar a través del cual se le concede amabilidad? ${ }^{42}$.

Resulta claro que no es este el significado que a bumanitas correspondió en el sermón XX. Ciertamente, carece de todo sentido que los credentes resultasen agradables a la divinidad una vez eliminada, por medio de la "molienda eclesiástica", su disposición para realizar actos amables.

En el sermón LXXIII, en tanto, el término fue empleado de manera evidentemente distinta. Tratando sobre la vigilia y el sueño ${ }^{43}$, señalaba Máximo que, desprovisto de todo vigor e incapaz de protegerse a sí mismo, el hombre era custodiado por la divinidad mientras dormía. Esta disponía entonces la oscuridad, a fin de que brindase «... a quienes están cansados la paz que su condición humana no proporcionaba»"44.

39. Como señala Mutzenbecher en el aparato crítico de su edición, el manuscrito G1 presenta para S. LXXXVII, 51 la variante humanitate en lugar de bumilitate, presente en todos los demás. La editora, sin embargo, tenía este sermón por espurio (MutzenBecher 1962, 356). A favor de la autenticidad del sermón se ha manifestado Weidmann, quien además de atribuir a Máximo 4 nuevas homilías, 2 pseudo-augustinianas y 2 consideradas anónimas- no encuentra motivos suficientes para cuestionar la autoría maximiana de los sermones XIV, LXIb, LXIc extr., LXXXVII, XC extr. y XCVII extr. (WeIDMANn 2014, 111-116; WeIDMANn 2018, 367).

40. S. XXI, 9-12: Festinauit ergo propterea Abraham sanctos uiros suscipere, ut hospitii consortio sanctitatis consortium mereretur; et dum conmunicat humanitatis obsequium, conmunicationem iustificationis acciperet.

41. S. XXI, 23-25: Quis autem nolit tali condicione sanctum tabernaculi sui humanitate suscipere, ut cum eo participans habitaculum participet sanctitatem?

42. S. LXXII, 64-66: Dic mibi, nonne si aliquid de tuo cuicumque largiris, expectas, ut tibi gratias agat, ut benedicat domum de qua ei humanitas sit tributa?

43. S. LXXIII, 27-45.

44. S. LXXIII, 42-43: ... et pacem fessis praestet obscuritas, quam non praestabat humanitas. 
Traducimos humanitas por "condición humana" porque entendemos que el término refiere aquí a lo que es propio de la constitución del hombre, en este caso la indefensión en ocasión del sueño.

De este modo, humanitas asumió en los sermones maximianos significados diversos: por un lado, daba cuenta de un acto altruista motivado por el afecto; por otro, de aquellas características específicas del hombre e inherentes a él. Descartado, como se dijo, que en la homilía ahora analizada la humanitas pudiese guardar alguna relación con la primera de estas acepciones, entendemos que en el sermón XX Máximo empleaba el término en el mismo sentido que en el sermón LXXIII, es decir, en referencia a un rasgo específico de la naturaleza humana. Este elemento que debía ser removido del espíritu por la "molienda eclesiástica» no era otro, creemos, que el peccatum de Adán, transmitido de modo congénito de generación en generación.

Así pues, a partir de las diversas y complementarias narraciones de un único proceso -aquel por medio del cual el individuo recuperaba su condición perdida y se hacía digno de la salvación- resulta factible establecer la relación existente a decir de Máximo entre la gentilitas, el peccatum y la humanitas. Esto, a su vez, permite comprender más acabadamente la gentilitas maximiana. En efecto, si cuanto hemos dicho es correcto, podemos concluir que, en los Sermones del obispo de Turín, gentilitas refería a un estadio de la existencia del individuo en el cual la originaria perfección de su espíritu se hallaba afectada por el antiguo pecado de Adán, inevitablemente transmitido a sus descendientes como rasgo particular de la constitución humana o bumanitas.

La continuidad de esta cuarta sección presenta menor relevancia a nuestros fines. Luego de una referencia a Sal. 51, 19 en la cual, en sintonía con lo apenas expresado, se destacaba que un espíritu humillado constituía un sacrificio para la divinidad (IV, $9=\mathrm{S}$. XX, 69-70), se retomaba el tópico del entendimiento del sabio y el error del necio. En tanto que para estos, a causa de la velocidad de su girar, el Evangelio se encontraba inmóvil, aquellos comprendían perfectamente su movimiento (IV, 10-11 $=\mathrm{S} . \mathrm{XX}, 70-74)$. La falta de entendimiento del insipiens era puesta en relación con su caecitas (IV, $11=\mathrm{S}$. XX, 73-74) y con el desprecio de los mandata (IV, 12 = S. XX, 74-76).

\subsection{Sección 5: la Iglesia y la Sinagoga}

Llegamos así a la sección final del sermón, la cual contiene, a modo de conclusión, el previsible elogio de la Iglesia con su contraparte, el repudio de la Sinagoga. Trabajando con la única piedra de la Ley, la tarea 
de esta última -a decir del autor- era inútil, ya que no molía sino que más bien dissipat et confringit $(\mathrm{V}, 1=\mathrm{S}$. XX, 77-80). A causa de ello, los judíos habían sido reprendidos tanto por Isaías como por Jesús (V, 2-3 = S. XX, 80-83). El error de la Sinagoga al creer que resultaba posible moler con la única piedra de la Ley, afirmaba Máximo, se remontaba al propio Moisés, quien había confundido las dos tablas pétreas de la Ley con las dos piedras requeridas para la molienda, ignorando que aquellas tablas eran figura de los dos testamentos (V, $5=\mathrm{S}$. XX, 84-88). Por su perfidia, la cruenta synagoga habría de experimentar un sufrimiento eterno; en tanto, en virtud de su molienda grata al Señor, la sancta ecclesia habría de ser adoptada in aeternam gloriam (V, 6-7 = S. XX, 88-91).

\section{CONClusión}

En base a nuestras indagaciones previas, hemos sostenido al iniciar este trabajo que el término gentilis designaba en la homilética maximiana al individuo que, todavía ajeno al conocimiento de la fe cristiana, permanecía en un estado de inocente padecimiento pasible de ser superado mediante su sometimiento a la instrucción eclesiástica. Tal circunstancia no solo ponía fin a sus dolencias, sino que le permitía además alcanzar la salvación. La concepción que respecto de los gentiles se presenta en el sermón XX, como se desprende del análisis realizado, refrenda plenamente esta tesitura. En efecto, afirmaba el autor en esta homilía que los gentiles podían aproximarse a la Iglesia y que mediante su instrucción eran despojados de toda impureza, deviniendo así agradables a la divinidad. A la vez que, de este modo, se confirma a partir del sermón XX la hipótesis planteada respecto del significado que Máximo atribuía a la gentilitas, resulta también refrendada su absoluta independencia respecto del paganismus tal como el obispo de Turín lo concebía. Ciertamente, el autor no asoció aquí a los gentiles ni con el rechazo del cristianismo ni con la consecuente muerte sin fin, rasgos distintivos del paganus en la prédica maximiana.

El examen realizado, además, consiente también una más acabada comprensión de la naturaleza de la gentilitas maximiana a partir de la relación que el obispo estableció en esta homilía entre ella, el peccatum y la bumanitas. Según hemos dicho, bumanitas remitía en el sermón XX, como en el LXXIII, a las características propias e inherentes de la condición humana. A partir de la consideración de diversos sermones en los cuales se trata sobre el proceso de asunción de la fe por parte del individuo, ha resultado posible apreciar que aquel elemento constitutivo del 
ser humano que el sujeto debía dejar atrás a fin de devenir agradable a la divinidad era el peccatum de Adán, heredado por todos los hombres, el cual contaminaba su espíritu apartándolo de la perfección originaria y sumiéndolo en la fragilidad de la gentilitas.

Así pues, nuestra comprensión del significado que al término gentilitas corresponde en los sermones de Máximo de Turín se enriquece a partir del análisis efectuado. En efecto, aquella caracterización realizada en nuestros estudios previos resulta ahora complementada por las siguientes dos circunstancias: por un lado, entendemos que aquel estado de inocencia sufriente al que el autor denominaba gentilitas era consecuencia del perjuicio causado en el spiritus de todos los individuos por el pecado adánico. El gentilis, pues, no era tal a causa de una voluntad desorientada, sino por el mero hecho de ser humano y, en consecuencia, portador de este rasgo propio de su humanitas; por otro, percibimos que, para el obispo de Turín, la gentilitas constituía uno entre los múltiples estadios en que el individuo podía hallarse en virtud de su situación espiritual, a saber: 1) secundum deum: estado original, signado por la pureza del espíritu, ajeno al error, al pecado, al sufrimiento y a la muerte misma; 2) gentilitas, estado natural del hombre en tanto que habitante del siglo. En él, a causa de un aspecto de su humanitas -esto es, la inevitable afectación del espíritu a causa del pecado de Adán-, el sujeto se hallaba sometido al error, al sufrimiento y a la muerte potencial en caso de que su condición no fuese superada; 3) aquel estado en el cual se encontraba el credens, el individuo entregado a la "molienda eclesiástica" una vez conocida la religión cristiana. Puesto que en su sermón LXV Máximo llamaba cathecumini $^{45}$ a los individuos que en tal situación se hallaban, bien podríamos denominar a este estadio cathechismus; 4) fidelitas o christianitas: estado propio de quien había consumado su tránsito desde la gentilitas hacia la fe una vez eliminada de su espíritu la mácula del pecado y recibido el bautismo. Aquí, el fidelis ${ }^{46}$ o $_{\text {christianus }}^{47}$-tales las denominaciones

45. S. LXV, 26-30: «El catecúmeno, en efecto, antes de ser bautizado, yace, está frío y pálido como el agua, mientras que el fiel es fuerte y rojo como el vino. El catecúmeno, digo, como el agua, no tiene ningún sabor, ningún aroma, ningún valor, y no es suficiente para el uso ni agradable para devolver la fuerza, ni resistente para conservarse, (Cathecuminus enim priusquam baptizetur sicut aqua iacet riget et pallet, fidelis autem sicut uinum fortis et rubeus est. Cathecuminus, inquam, sicut aqua nullius saporis nullius odoris nullius est praetii, nec sufficiens ad usum nec delectabilis ad reficiendum nec tolerabilis ad seruandum).

46. Véase la nota previa.

47. S. LXV, 36-45: "Con razón el vino es comparado con el fiel. Así como, en efecto, todas las cosas perecen con el paso del tiempo a causa de la naturaleza de las creaturas y únicamente el vino mejora con el tiempo, así también mientras todo el género humano 
que Máximo le atribuía en el sermón LXV-, recuperaba la pureza de su espíritu y, con ella, la gracia de la inmortalidad; 5) paganismus: situación en que se hallaban quienes, habiendo conocido la uera fides, habían rechazado portare iugum domini, mereciendo en consecuencia la muerte eterna $^{48}$. En tal sentido, paganus habría sido para Máximo tanto aquel sujeto que se había negado a devenir credens al entrar en contacto con el cristianismo como quien, habiendo incluso atravesado el proceso de "molienda eclesiástica» y alcanzado la condición de fidelis, había luego exhibido unas conductas y unas creencias propias del ya superado estadio de gentilitas, perdiendo por ello la gracia adquirida.

Este esquema, por otra parte, explica el hecho de que el obispo en ninguna ocasión dirigiese reproche alguno contra la gentilitas en sí misma ni contra unos gentiles a los cuales, como se desprende de lo dicho, estimaba víctimas pasivas e inocentes de su condición. En efecto, toda vez que alguna invectiva o amenaza emerge en el contexto de un sermón en que la cuestión gentil se hace presente, estas tienen como destinatarios a los propios miembros de la comunidad cristiana -a los fideles-, por conservar en sus vidas cotidianas prácticas y/o creencias de un estadio ya superado ${ }^{49}$.

Finalmente, vale la pena insistir ${ }^{50}$ sobre el aporte que estas consideraciones realizan respecto de la situación en que la empresa de cristianización se encontraba en Turín y sus inmediaciones hacia finales del siglo Iv y comienzos del v. La preocupación de Máximo por la gentilitas en tanto que estadio previo al conocimiento del cristianismo -y no ya por un "paganismo" prácticamente ausente en sus sermones- podría dar cuenta de los escasos progresos efectivamente realizados por la noua fides entre unas poblaciones cuyo potencial para devenir credentes, cathecumini y fideles el obispo daba por descontado.

perece con la edad, solo el cristiano mejora con el tiempo. Y así como el vino reduce día a día su aspereza, adquiere la dulzura de su sabor y la suavidad de su olor, así también el cristiano con el paso del tiempo, reduciendo la aspereza de sus errores, recibe para sí la sabiduría de la divinidad y el agradable aroma de la Trinidad" (Recte autem uino conparatur fidelis. Sicut enim ex cunctarum creaturarum substantia omnis res uetustate deperit solum uinum proficit uetustate, ita et ex omni genere hominum cunctis antiquitate pereuntibus solus christianus proficit uetustate. Et sicut uinum in dies singulos asperitatem suam decoquens saporis dulcedinem suauitatem odoris adquirit, ita et christianus successu temporis delictorum suorum asperitatem decoquens sapientiam sibi diuinitatis beneolentiam trinitatis adsumit).

48. S. XLVIII, 96. Véase Noce 2019a, 186-191. $11-20$.

49. S. XXX, 66-73; S. LXIc extr., 65-72; S. LXIII, 2-9; S. LXXIII, 46-50; S. XCVIII extr., 50. Noce 2019a, 198-199. 
6. REFERENCIAS BIBLIOGRÁFICAS

Adriaen, Marc (1957): Expositio Evangelii Secundum Lucam, en AdRIAEN, Marc, Ballerini, Paolo Angelo (eds.): Sancti Ambrosii Mediolanensis Opera. Pars IV (CCSL, XIV), Turnhout.

Ariano, Maria Luisa (2014): "La condanna dell'idolatria nell'omiletica dell'Italia settentrionale di fine IV secolo", Auctores Nostri, 14, 129-163.

Ariano, Maria Luisa (2017): "Polemica per immagini aduersus paganos nell'omiletica dell'Italia settentrionale di fine IV secolon, Auctores Nostri, 18, 11-35.

Ariano, Maria Pia Amelia (2014): "La polemica antipagana in Massimo di Torino", Auctores Nostri, 14, 211-242.

Banterle, Gabriele (ed.) (1991): San Massimo di Torino. Sermoni, MilanoRoma.

Banterle, Gabriele (trad.), Petri, Sara (intr. y notas) (2003): Massimo di Torino. Sermones, Roma.

Beatrice, Pier Franco (2005): "On the Meaning of "Profane" in the PaganChristian Conflict of Late Antiquity. The Fathers, Firmicus Maternus and Porphyry before the Orphic "Prorrhesis" (OF 245.1 Kern)", Illinois Classical Studies, 30, 137-165.

Beatrice, Pier Franco (2010): "Semantic Shifts in Augustine's Use of the Word Profanus", en Rebillar, Eric, Sotinel, Claire (eds.), Les frontières du profane dans l'Antiquité Tardive, Roma, 37-53.

Bolgiani, Franco (1997): "Militari e preti, potenti e servi, ariani ed eretici, ebrei e barbari", en Sergi, Giuseppe (ed.): Storia di Torino. I. Dalla preistoria al comune medievale, Torino, 278-286.

Bolgiani, Franco (1998): "La diocesi di Torino nel IV-V secolo sotto i due Massimo", en Mercando, Liliana, Micheletto, Egle (eds.): Archeologia in Piemonte. Volume III. Il Medioevo, Torino, 121-131.

Bongiovanni, Pietro (1952): S. Massimo vescovo di Torino e il suo pensiero teologico. Estratto dalla dissertazione di laurea. Pontificium Athenaeum Salesianum, Facultas Theologica, Theses ad lauream-N. 6, Torino.

De Filippis Cappai, Chiara (1995): Massimo Vescovo di Torino e il suo tempo, Torino.

De Filippis Cappai, Chiara (1999): "Società e cristianesimo a Torino al tempo di Massimo", en Atti del Convegno Internazionale di Studi su Massimo di Torino nel XVI Centenario del Concilio di Torino (398) (Torino, 13-14 marzo 1998), Torino, 50-68.

Devoti, Domenico (1999): "Massimo oratore", en Atti del Convegno Internazionale di Studi su Massimo di Torino nel XVI Centenario del Concilio di Torino (398) (Torino, 13-14 marzo 1998), Torino, 99-115. 
Di Mauro, Nicola (2001): La paterna tenerezza di un pastore d'anime. San Massimo vescovo di Torino, Torino.

Eger, Gerhard (2014): Magna Pollutio: Saint Maximus on the Survival of Paganism in 4 th Century Turin. A senior thesis submitted to the Classics Department of Princeton University in partial fulfilment of the requirements for the degree of Bachelor of Arts, Princeton.

Faller, Otto (ed.) (1955): Sancti Ambrosii Opera. Pars VII (CSEL LXXIII), Wien.

Gallesio, Filippo (ed.) (1975): S. Massimo di Torino, Sermoni, Alba.

Hamman, Adalbert-Gautier (intr.), Plazanet-Siarri, Nadine (trad.) (1996): Maxime de Turin prêche l'année liturgique, Paris.

LizzI, Rita (1989): Vescovi e strutture ecclesiastiche nella città tardoantica ('Italia Annonaria nel IV-V secolo d.C.), Como.

Mariani Puerari, Milena (ed.) (1999): Massimo di Torino, Sermoni Liturgici, Milano.

Maritano, Mario (1999): "La sacra scrittura nei Sermoni e nel ministero episcopale di Massimo di Torino", en Atti del Convegno Internazionale di Studi su Massimo di Torino nel XVI Centenario del Concilio di Torino (398) (Torino, 13-14 marzo 1998), Torino, 116-166.

MerkT, Andreas (1997): Maximus I. von Turin: die Verkündigung eines Bischofs der früben Reichskirche im zeitgeschichtlichen, gesellschaftlichen und liturgischen Kontext, Leiden-New York-Köln.

Modemann, Martin (1995): Die Taufe in den Predigten des hl. Maximus $v$. Turin, Frankfurt am Main.

Mutzenbecher, Almut (1961): "Bestimmung der echten Sermones des Maximus Taurinensis», Sacris Erudiri, 12, 197-293.

Mutzenbecher, Almut (ed.) (1962): Maximi episcopi Taurinensis sermones (CCSL XXIII), Turnhout.

Noce, Esteban (2017): "Cristianismo y gentilitas en los Sermones de Máximo de Turín: consideraciones críticas sobre el estado de la cuestión", Vetera Christianorum, 54, 173-204.

Noce, Esteban (2019a): "Gentilitas y paganismus en los sermones de Máximo de Turín: reconsideración de una sinonimia infundada", Annali di Storia dell'Esegesi, 36, 1, 171-199.

Noce, Esteban (2019b): "En torno a la independencia semántica de los términos gentilitas y paganismus en los Sermones de Máximo de Turín. Verificación de una hipótesis», Antiquité Tardive, 27, 279-301.

Padovese, Luigi (1985): Sermoni di S. Massimo di Torino, 2 volúmenes, Casale Monferrato.

Padovese, Luigi (1999): "Massimo vescovo di Torino", en Atti del Convegno Internazionale di Studi su Massimo di Torino nel XVI Centenario del Concilio di Torino (398) (Torino, 13-14 marzo 1998), Torino, 85-98. 
DE MÁXIMO DE TURÍN (...398-...423). TRADUCCIÓN Y COMENTARIO

Ramsey, Boniface (ed.) (1989): The Sermons of St. Maximus of Turin, New York-Mahwah.

SAVIO, Fedele (1971 [1. a ed. 1898]): Gli antichi vescovi d'Italia, dalle origini al 1300, descritti per regioni. Il Piemonte, Bologna.

SchenkL, Karl (ed.) (1896): Sancti Ambrosii Opera. Pars prima (CSEL, XXXII), Praga-Wien-Leipzig.

Spinelu, Lino (1983): Maria nei Sermoni di S. Massimo vescovo di Torino, Vicenza.

Tamassia, Nino (1911): "L’ultima età romana nei sermoni attribuiti a s. Massimo vescovo di Torino", Atti del Reale Istituto Veneto di Scienze, Lettere ed Arti, LXX, II, 421-435.

Trisoglio, Federico (2001): «S. Ambrogio e l'esegesi di S. Massimo di Torino", Annali di Storia dell'Esegesi, 18, 2, 615-635.

Van Nuffelen, Peter (2011): "Eusebius of Caesarea and the Concept of Paganism", en Lavan, Luke, Mulryan, Michael (eds.): The Archaeology of Late Antique "Paganism", Leiden-Boston, 89-109.

Weidmann, Clemens (2014): "Vier unerkannte Predigten des Maximus von Turin", Sacris Erudiri, 53, 99-130.

Weidmann, Clemens (2018): «Maximus of Turin. Two Preachers of the Fifth Century", en Dupont, Anthony, Boodts, Shari, Partoens, Gert, LeEmans, Johan (eds.): Preaching in the Patristic Era. Sermons, Preachers, and Audiences in the Latin West, Leiden-Boston, 347-372.

ZANGARA, Vincenza (1992): «I 'mandata' divini nella predicazione di Massimo di Torino", Annali di Storia dell'Esegesi, 9, 2, 493-518.

ZANGARA, Vincenza (1994): "Intorno alla collectio antiqua dei sermoni di Massimo di Torino", Revue des Etudes Augustiniennes, 40, 435-451.

Zangara, Vincenza (1995): «San Massimo di Torino», en Bosio, Guido, Dal Covolo, Enrico, Maritano, Mario (eds.): Introduzione ai Padri della Chiesa. Secoli IV e V, Torino, 48-59. 
